\title{
HIP DISEASE IN ADULTS WITH DOWN SYNDROME
}

\author{
M. TIMOTHY HRESKO, JOSEPH C. MCCARTHY, MICHAEL J. GOLDBERG
}

From Tufts University School of Medicine, Boston, USA

The life expectancy of patients with Down syndrome has increased significantly in recent years. Hip abnormalities occur in children with this syndrome but little is known about their natural history in later life.

In 65 adults with Down syndrome we found hip abnormalities in $28 \%$, and this was statistically correlated with walking ability. A subgroup of 18 patients was followed by serial examination; this showed that hip instability occurred in adulthood and became worse with time. In some patients, hip instability started after skeletal maturity.

J Bone Joint Surg [ Br] 1993; 75-B:604-7.

Received 29 September 1992; Accepted after revision 21 January 1993

Little has been reported about the natural history of orthopaedic disorders associated with Down syndrome in adults. Children with Down syndrome are known to have joint laxity, which is present at birth and persists into adolescence (Parker and James 1985). Hypermobility is associated with a high incidence of patellar instability, pes planus, metatarsus primus varus, scoliosis, hip dysplasia and increased atlantoaxial mobility (Diamond, Lynne and Sigman 1981). Only in recent years has a large number of patients with Down syndrome survived into the fourth decade and beyond and their functional disabilities have not been well documented.

Bennet et al (1982) reported that the hip abnormalities in children with Down syndrome included acute dislocation, habitual dislocation and progressive subluxation associated with hip dysplasia. They found a $45 \%$ incidence of dislocation in a group of institutionalised patients, and noted that some patients with hip dislocation could, nevertheless, walk without pain. Roberts et al (1980) reviewed 66 adult patients with Down syndrome and found only one case of dysplasia and seven of

M. T. Hresko, MD, Assistant in Orthopaedic Surgery

Children's Hospital, 300 Longwood Avenue, Boston, Massachusetts 02115, USA

J. C. McCarthy, MD, Clinical Associate Professor of Orthopaedics

M. J. Goldberg, MD, Professor and Chairman, Department of Orthopaedics

Tufts University Medical School, New England Medical Centre, 750 Washington Street, Boston, Massachusetts 02111, USA.

Correspondence should be sent to Dr M. T. Hresko.

(C)1993 British Editorial Society of Bone and Joint Surgery $0301-620 \times / 93 / 4602 \$ 2.00$ osteoarthritis. These observations were not in accord with our experience, and we therefore reviewed a group of adult patients with Down syndrome.

\section{PATIENTS AND METHODS}

We identified 127 patients with Down syndrome from the records of the Shriver Center for Mental Retardation in Waltham, MA. These included patients in community residential housing as well as those who required institutional care. All available radiographs were surveyed for views of the hip that may have been included on pelvic, abdominal, or urinary tract radiographs. We retrieved adequate views of the hips of 65 patients ( 36 male and 29 female), and correlated those with medical records and clinical examinations, noting associated medical and skeletal problems. Variations in radiographic projections used in this study were: acetabular angle as measured by Sharp (1961) (normal less than $45^{\circ}$ ), acetabular roof angle (normal greater than $0^{\circ}$ ), centreedge angle of Wiberg (normal greater than $25^{\circ}$; Wiberg 1939), and joint space width (normal equal to or greater than $4 \mathrm{~mm}$ ). Hip subluxation was recorded as mild if less than $25 \%$ of the head was uncovered, moderate if $25 \%$ to $50 \%$ of the head was uncovered, and severe if this was over $50 \%$.

Serial radiographs were available for at least three years for 18 of the 65 patients. This subgroup was reviewed for any change of function or progression of disease over time. All these patients had new anteroposterior and lateral radiographs of the hips at the time of the latest follow-up.

Statistical analysis was by the StatExact program (Cytel Software Co, Cambridge, MA).

\section{RESULTS}

The 65 patients ( 130 hips) had a mean age of 40 years ( 14 to 70). Details are given in Table I.

Radiographs. The radiographic appearances were within normal limits in 47 of the 65 patients (72\%). Eighteen patients had radiographic evidence of hip pathology, unilateral in 7 and bilateral in 11. Thus 29 of the 130 hips $(22 \%)$ showed radiographic abnormalities (Table II).

In three patients $(4.6 \%)$ five hips were dislocated. All three had severely limited walking ability and were wheelchair-bound except for supervised therapeutic exercises. Severe subluxation was found in two patients: 
Table I. Age distribution and ambulatory status of 65 adult patients with Down syndrome

\begin{tabular}{|c|c|c|c|c|}
\hline \multirow{2}{*}{$\begin{array}{l}\text { Age } \\
(\mathbf{y r})\end{array}$} & \multirow[b]{2}{*}{ Number } & \multirow[b]{2}{*}{ Ambulation } & \multicolumn{2}{|l|}{ Hips } \\
\hline & & & Normal & Absormal \\
\hline 14 to 19 & 4 & $\begin{array}{l}\text { Wheelchair } \\
\text { Exercise/household } \\
\text { Community }\end{array}$ & $\begin{array}{l}0 \\
0 \\
4\end{array}$ & $\begin{array}{l}0 \\
0 \\
0\end{array}$ \\
\hline 20 to 29 & 10 & $\begin{array}{l}\text { Wheelchair } \\
\text { Exercise/household } \\
\text { Community }\end{array}$ & $\begin{array}{l}1 \\
0 \\
7\end{array}$ & $\begin{array}{l}0 \\
0 \\
2\end{array}$ \\
\hline 30 to 39 & 22 & $\begin{array}{l}\text { Wheelchair } \\
\text { Exercise/household } \\
\text { Community }\end{array}$ & $\begin{array}{r}0 \\
1 \\
12\end{array}$ & $\begin{array}{l}3 \\
2 \\
4\end{array}$ \\
\hline 40 to 49 & 11 & $\begin{array}{l}\text { Wheelchair } \\
\text { Exercise/household } \\
\text { Community }\end{array}$ & $\begin{array}{l}1 \\
1 \\
6\end{array}$ & $\begin{array}{l}0 \\
2 \\
1\end{array}$ \\
\hline 50 to 59 & 10 & $\begin{array}{l}\text { Wheelchair } \\
\text { Exercise/household } \\
\text { Community }\end{array}$ & $\begin{array}{l}2 \\
1 \\
5\end{array}$ & $\begin{array}{l}1 \\
0 \\
1\end{array}$ \\
\hline 60 to 70 & 8 & $\begin{array}{l}\text { Wheelchair } \\
\text { Exercise/household } \\
\text { Community }\end{array}$ & $\begin{array}{l}3 \\
0 \\
3\end{array}$ & $\begin{array}{l}1 \\
1 \\
0\end{array}$ \\
\hline Total & 65 & $\begin{array}{l}\text { Wheelchair } \\
\text { Exercise/household } \\
\text { Community }\end{array}$ & $\begin{array}{r}7 \\
3 \\
37\end{array}$ & $\begin{array}{l}5 \\
5 \\
8\end{array}$ \\
\hline
\end{tabular}

one with unilateral involvement remained a community ambulator at the age of 37 years; the other, with bilateral subluxation, was a household ambulator after total hip replacement. Less severe subluxation or dysplasia was present in 13 hips in seven patients. Other conditions diagnosed from the radiographs included protrusio acetabuli in one patient, slipped capital femoral epiphysis in one, and osteoarthritis without acetabular dysplasia in six hips of four patients.

Walking function. Of the 47 patients with radiographically normal hips (mean age 39.7 years, SD 14.2), seven were wheelchair-dependent, three were household ambulators, and 37 were community ambulators (Table I). Of the 18 patients with hip disease (mean age 40.7 years, SD 11.7), five were wheelchair-dependent, five were household or exercise ambulators, and eight were community ambulators. The percentage of patients with abnormal hips differed in each ambulation group, showing a significant statistical heterogeneity $(p=$ 0.121 ; Mehta's adaptation of the Fisher exact test for tables).

A number of other medical conditions including Alzheimer's disease, Parkinsonism, cardiac abnormalities, and cervical instability were found in the study group, but there was no association between these conditions and the presence of hip disease.

Serial radiographs. Eighteen patients had repeated radiographs over at least three years (Table III). In this group, the mean age at latest follow-up was $\mathbf{4 2 . 4}$ years (SD 14.1) and the mean follow-up was 10.2 years (SD 5.2). At the time of the initial film, 11 of the 18 patients had apparently normal hips. Of these 11 , seven remained
Table II. Age, diagnosis and ambulatory status of 18 adult patients with Down syndrome and abnormal hip radiographs

\begin{tabular}{ccll}
\hline Case & $\begin{array}{c}\text { Ase } \\
(\mathbf{y r})\end{array}$ & Diagaceds & $\begin{array}{l}\text { Ambalatory } \\
\text { status }\end{array}$ \\
\hline 1 & 35 & Bilateral dysplasia & Household \\
2 & 42 & Unilateral dysplasia & Community \\
3 & 37 & Bilateral dysplasia & Wheelchair \\
4 & 24 & Bilateral dysplasia & Community \\
5 & 36 & Mild bilateral subluxation & Wheelchair \\
6 & 22 & Mild bilateral subluxation & Community \\
7 & 30 & Mild bilateral subluxation & Community \\
8 & 37 & Severe unilateral subluxation & Community \\
9 & 40 & Severe bilateral subluxation & Household \\
10 & 39 & Bilateral dislocation & Exercise \\
11 & 34 & Unilateral dislocation & Wheelchair \\
12 & 55 & Bilateral dislocation & Wheelchair \\
13 & 60 & Unilateral SCFE* & Wheelchair \\
14 & 39 & Unilateral protrusio acetabuli & Community \\
15 & 43 & Mild unilateral OA $†$ & Household \\
16 & 64 & Mild bilateral OA & Household \\
17 & 37 & Moderate bilateral OA & Community \\
18 & 58 & Moderate unilateral OA & Community \\
\hline & &
\end{tabular}

- slipped capital femoral epiphysis

† osteoarthritis

Table III. Results of serial hip radiographs in 18 adults with Down syndrome

\begin{tabular}{lll}
\hline Initial appearance & $\begin{array}{l}\text { Mean } \\
\text { follow-up } \\
(\mathbf{y})\end{array}$ & Appearance and changes \\
\hline Normal $(n=11)$ & 9.0 & $\begin{array}{l}7 \text { normal } \\
4 \text { deformity } \\
1 \text { dislocation } \\
3 \text { mild subluxation }\end{array}$ \\
& & $\begin{array}{l}\text { 4 no change } \\
2 \text { progression } \\
1 \text { subluxation to dislocation } \\
\text { 1 moderate to severe dysplasia } \\
1 \text { with new disease in contralateral hip }\end{array}$ \\
\hline
\end{tabular}

normal after an average follow-up of 9.0 years, but the other four (36\%) had developed hip disease on follow-up films. Three patients showed mild dysplasia and one had a dislocation (Fig. 1).

Of the seven patients with hip abnormalities on the initial films, two showed progression after a mean period of 14.1 years. One had progressed from subluxation to dislocation and the other had progressed from moderate to severe dysplasia and required a total hip replacement. In one of them, a previously normal contralateral hip had become dysplastic.

As a result of these changes radiographic hip 


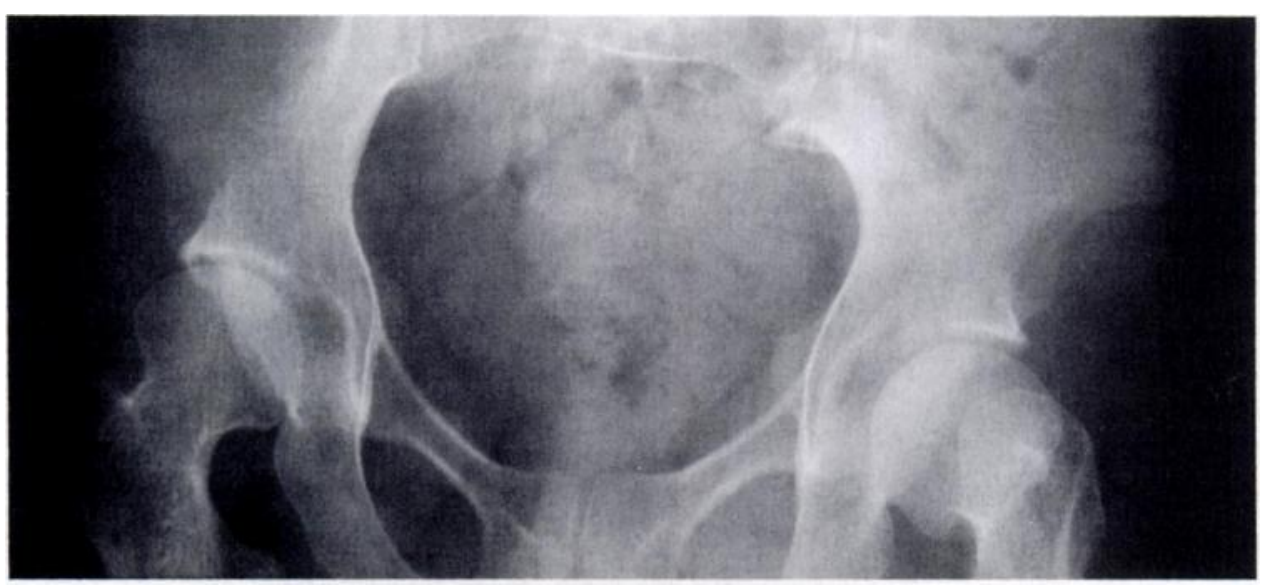

Fig. la

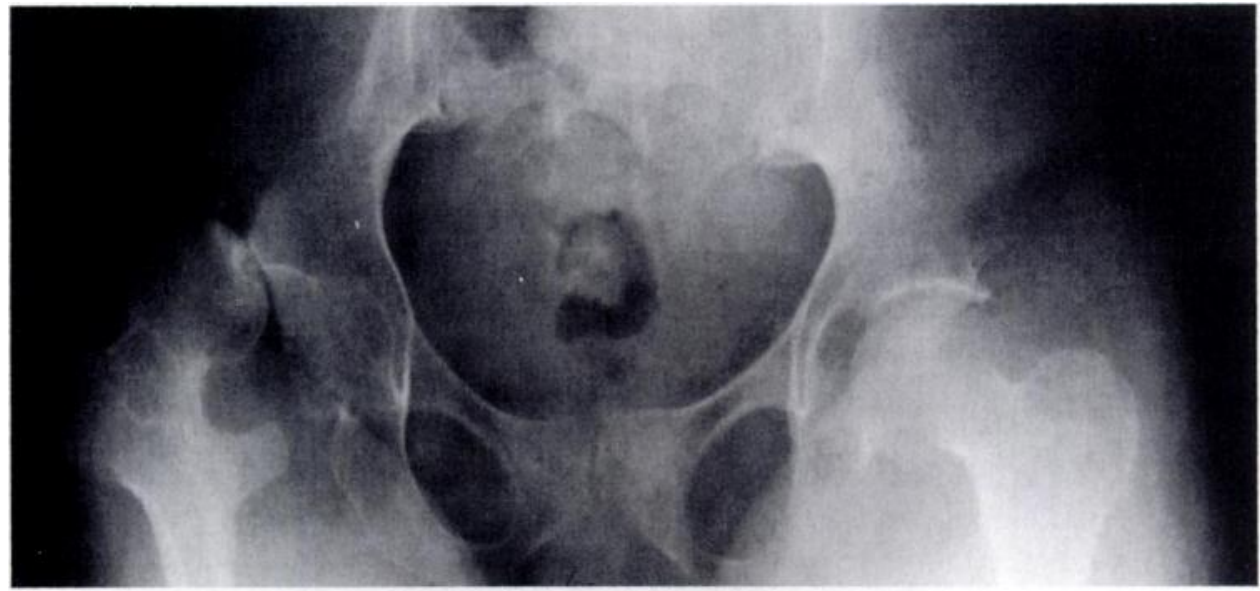

Fig. 1b

Figure la - Case 11. Pelvic radiograph of a 31-year-old man with Down syndrome. Figure $1 \mathrm{~b}$ - Three years later there is dislocation of the right hip.

pathology was present in 11 of the 18 patients $(61 \%)$ at latest follow-up; there was dysplasia in nine, osteoarthritis in one, and protrusio acetabuli in one.

\section{DISCUSSION}

Patients with Down syndrome are living longer (Thase 1982), and as they age the manifestations of the chromosomal abnormality become evident in many body systems. Post-mortem studies have shown that all such patients aged 40 years or more have involvement of the central nervous system with neuropathological changes similar to those seen in Alzheimer's disease (Wisniewski, Wisniewski and Wen 1985). These changes lead to clinically significant mental retardation and loss of motor skills, and it is therefore difficult to isolate the influence of musculoskeletal deterioration from that of the other systems. It is evident, however, that hip disease is common, and that it does affect function: there was a significant difference in the proportion able to be independent community ambulators between patients with radiographically normal and abnormal hips.

Published information on hip disorders in patients with Down syndrome is based on findings in children and young adults. Our study shows that hip disease is not unusual in adults with this syndrome: $18 \%$ of our adult patients had hip dysplasia, establishing a prevalence rate of at least $9 \%$ (12 of 127) in our whole population of community and institutionalised patients. Two-thirds of the hip patients had gross subluxation or dislocation.

The finding of a normal hip at maturity does not preclude later subluxation or dislocation. The hypermobility of joints associated with Down syndrome is known to persist into teenage years (Parker and James 1985), and we have now observed the appearance of dysplasia and subluxation in previously normal hips in four of 11 adult patients. The most common change was the appearance of mild acetabular dysplasia but one hip dislocated in an adult non-ambulator with a normal acetabulum. This suggests that more cases of hip disease will appear as the population ages. There does not seem to be a 'safe' age at which hip stability can be guaranteed.

Progression of hip disease after skeletal maturity was not reported for younger patients with Down syndrome by Bennet et al (1982), but in addition to our radiographic findings we found loss of function. As hips 
progressed from mild to severe subluxation or dislocation, the deterioration in walking ability often precluded community-based living.

Walking ability also decreased markedly with age. In those with normal radiographs, 12 of 13 were still able to walk at the age of 40 years, but by the age of 60 to 70 years only half were community ambulators. This deterioration with ageing is well recognised but the significance of hip disease has not previously been appreciated (Paulson 1971; Bennet et al 1982). Most of our patients with hip disease could not function as community ambulators after the age of 30 years.

Conclusions. Hip disease is common in adults with Down syndrome. Hip dysplasia may develop with ageing and may cause progressive loss of walking ability.

No benefits in any form have been received or will be received from a commercial party related directly or indirectly to the subject of this article.

\section{REFERENCES}

Bennet GC, Rang M, Roye DP, Aprin H. Dislocation of the hip in trisomy 21. J Bone Joint Surg [Br] 1982; 64-B :289-94.

Diamond LS, Lynne D, Sigman B. Orthopaedic disorders in patients with Down's Syndrome. Orthop Clin North Am 1981; 12 :57-71.

Parker AW, James B. Age changes in the flexibility of Down's Syndrome children. J Ment Defic Res 1985; 29:207-18.

Paulson GW. Failure of ambulation in Down's Syndrome: a clinical survey. Clin Pediatr (Phila) 1971; 10:265-7.

Roberts GM, Starey N, Harper P, Nuki G. Radiology of the pelvis and hips in adults with Down's Syndrome. Clin Radiol 1980; 31 :475-8.

Sharp IK. Acetabular dysplasia : the acetabular angle. J Bone Joint Surg [Br] 1961 ; 43-B:268-72.

Thase ME. Longevity and mortality in Down's Syndrome. J Ment Defic Res 1982; $26: 177-92$.

Wiberg G. Studies on dysplastic acetabula and congenital subluxation of the hip joint: with special reference to the complication of osteoarthritis. Acta Chir Scand 1939; 83:Suppl 58.

Wisniewski KE, Wisniewski HM, Wen GY. Occurrence of neuropathological changes and dementia of Alzheimer's disease in Down's Syndrome. Ann Neurol 1985; 17:278-82. 